Original Article

\title{
Characteristics of Purple Sweet Potato Yogurt and Its Effect on Lipid Profiles of Sprague Dawley Rats Fed with High Fat Diet
}

Lily Arsanti Lestari ${ }^{12^{*}}$, Qisthira Swasti Amirina ${ }^{1}$, Dina Septari Anindyah ${ }^{1}$, Ainun Nisa ${ }^{1}$, Annisa Nurul Huda $^{1}$, Widiyani Indrianingrum ${ }^{1}$, Prasetyastuti ${ }^{3}$, and Nurliyani ${ }^{4}$

1 Department of Nutrition \& Health, Faculty of Medicine, Public Health and Nursing, Universitas Gadjah Mada, Jl. Farmako, Sekip Utara, Yogyakarta, 55281 Indonesia

2 Institute for Halal Industry and System, Universitas Gadjah Mada, Yogyakarta, 55281, Indonesia

${ }^{3}$ Department of Biochemistry, Faculty of Medicine, Public Health and Nursing, Universitas Gadjah Mada, Jl. Farmako, Sekip Utara, Yogyakarta, 55281 Indonesia

4 Faculty of Animal Science, Universitas Gadjah Mada, Jl. Fauna No.3, Bulaksumur, Yogyakarta 55281 Indonesia

*Corresponding author: Lily Arsanti Lestari I Email: lily_al@ugm.ac.id

Received: 16 June 2020; Revised: 24 July 2020; Accepted: 5 August 2020; Published: 26 October 2020

\begin{abstract}
The objectives of this study were to evaluate the effect of purple sweet potato (PSP) yogurt on the lipid profile of Sprague Dawley rats. The PSP yogurt was made from fresh PSP (F-PSP) and its powder (P-PSP). The viscosity, $\mathrm{pH}$, total titratable acid, proximate, antioxidant activity, anthocyanin content, and total lactic acid bacteria (LAB) between those yogurts were compared. Selected yogurt was given to Sprague Dawley rats for 4 weeks. Serum lipid profiles were determined after 2 and 4 weeks of treatment. F-PSP yogurt has better physical, chemical and microbiological properties compared to P-PSP yogurt. The serum cholesterol and triglyceride levels in F-PSP yogurt group was not significantly different compared to control group (P>0.05). However, the reduction of serum LDL cholesterol in F-PSP yogurt group was significantly higher than control group. The serum HDL cholesterol in the yogurt group decreased after 2 weeks of treatment, but it increased after 4 weeks of treatment. F-PSP yogurt could be used as an alternative functional food that could lower the blood cholesterol level because of the ability to reduce the LDL cholesterol level.
\end{abstract}

Keywords: yogurt characteristics; purple sweet potato yogurt; lipid profiles; high fat diet

\section{INTRODUCTION}

Hyperlipidemia is a known risk factor for Coronary Heart Diseases (CHD). According to Brown et al. [1], blood cholesterol level is one of the risk factors that play an important role in the development of CHD. In addition, according to the Adult Treatment Panel (ATP) III, elevation of triglyceride levels was found as an independent risk factor for CHD [2]. There is a positive correlation between the levels of LDL and total cholesterol in the blood. On the contrary, it is found that the HDL cholesterol in people with CHD was lower than those who are not suffering from CHD.

Purple sweet potato has a high potency as a functional food because it is rich in nutrients and antioxidants components such as phenolic acid, anthocyanins, and tocopherols [3]. 
Anthocyanins in purple sweet potato could act as free radical scavengers, which can prevent the onset of aging, cancer, and degenerative diseases such as arteriosclerosis. Some people consider that sweet potato is a lower class food. Therefore, it is necessary to increase the utilization of purple sweet potato through development of the derivative products such as cookies, biscuit, and even yogurt. This modification could increase the value of sweet potato.

The quantity and quality of the nutrient may change during yogurt processing. According to Lohachoompol et al. [4], there are no significant differences in the antioxidant activity of anthocyanin extracts in frozen, dried, or fresh blueberries. However, fermentation may increase the content of nutrients, digestibility, and flavor. In addition, the fermentation process in the processing of yogurt can increase its antioxidant activity. Kim et al. [5] found that heat treatment could increase the antioxidant activity of polyphenols and flavonoids. Based on this finding, we developed purple sweet potato yogurt from fresh purple sweet potato and its powder form. Purple sweet potato powder undergoes a drying process while the fresh purple sweet potato undergoes a steaming process. In the powdering process, drying process is done in cabinet dryer at a temperature of $50^{\circ}$ $\mathrm{C}$ for 24 hours. Whereas, steaming process is done using water vapor at a temperature of $100{ }^{\circ} \mathrm{C}$ for 30 minutes.

The objectives of this study were to develop yogurt product made from purple sweet potato; to characterize the physical property (viscosity), chemical properties (proximate, $\mathrm{pH}$ value, total titratable acid, total anthocyanin, antioxidant activity), microbiological property (total lactic acid bacteria ( LAB); and to evaluate the effect of purple sweet potato yogurt on lipid profiles (total cholesterol, LDL cholesterol, HDL cholesterol, and triglyceride) of Sprague Dawley rats fed high fat diet.

\section{MATERIALS AND METHODS}

\subsection{Starter preparation}

Lactobacillus bulgaricus FNCC0041 and Streptococcus thermophilus FNCC0040 were obtained from Food and Nutrition Culture Collection (FNCC), Center for Food and Nutrition Studies, Universitas Gadjah Mada, Yogyakarta, Indonesia. The bacteria were kept at $-20{ }^{\circ} \mathrm{C}$ in $10 \%$ skim milk (w/v) and 10\% glycerol (w/v). Frozen culture was streaked onto MRS agar (Merck), followed by incubation at $37{ }^{\circ} \mathrm{C}$ for $24-48 \mathrm{~h}$. Then, one colony from the plate was transferred into $10 \mathrm{~mL}$ of MRS broth (Merck) and incubated overnight. Bacteria were grown on MRS broth medium, incubated at $37^{\circ} \mathrm{C}$ for $18-20 \mathrm{~h}$. The cell suspension was centrifuged at 3,000 rpm for 15 minutes, the pellet was washed with $0.85 \% \mathrm{NaCl}$, and centrifuged at 3,000 rpm for 15 minutes. The pellet was suspended in $10 \%$ sterile skim milk and incubated at $37{ }^{\circ} \mathrm{C}$ for $18-20 \mathrm{~h}$.

\subsection{Yogurt processing}

Purple sweet potato yogurt was made from fresh purple sweet potato and its powder form. The flowchart of yogurt preparation is shown in Figure 1. The selected yogurt (F-PSP) was administered to Sprague Dawley rats. During animal experiment, the purple sweet potato yogurt was made once a week. The $\mathrm{pH}$ value of sweet potato yogurt was ranging from 3.49-4.14. The number of $\mathrm{LAB}$ was ranging from $10^{8}-10^{9} \mathrm{CFU} / \mathrm{g}$. 


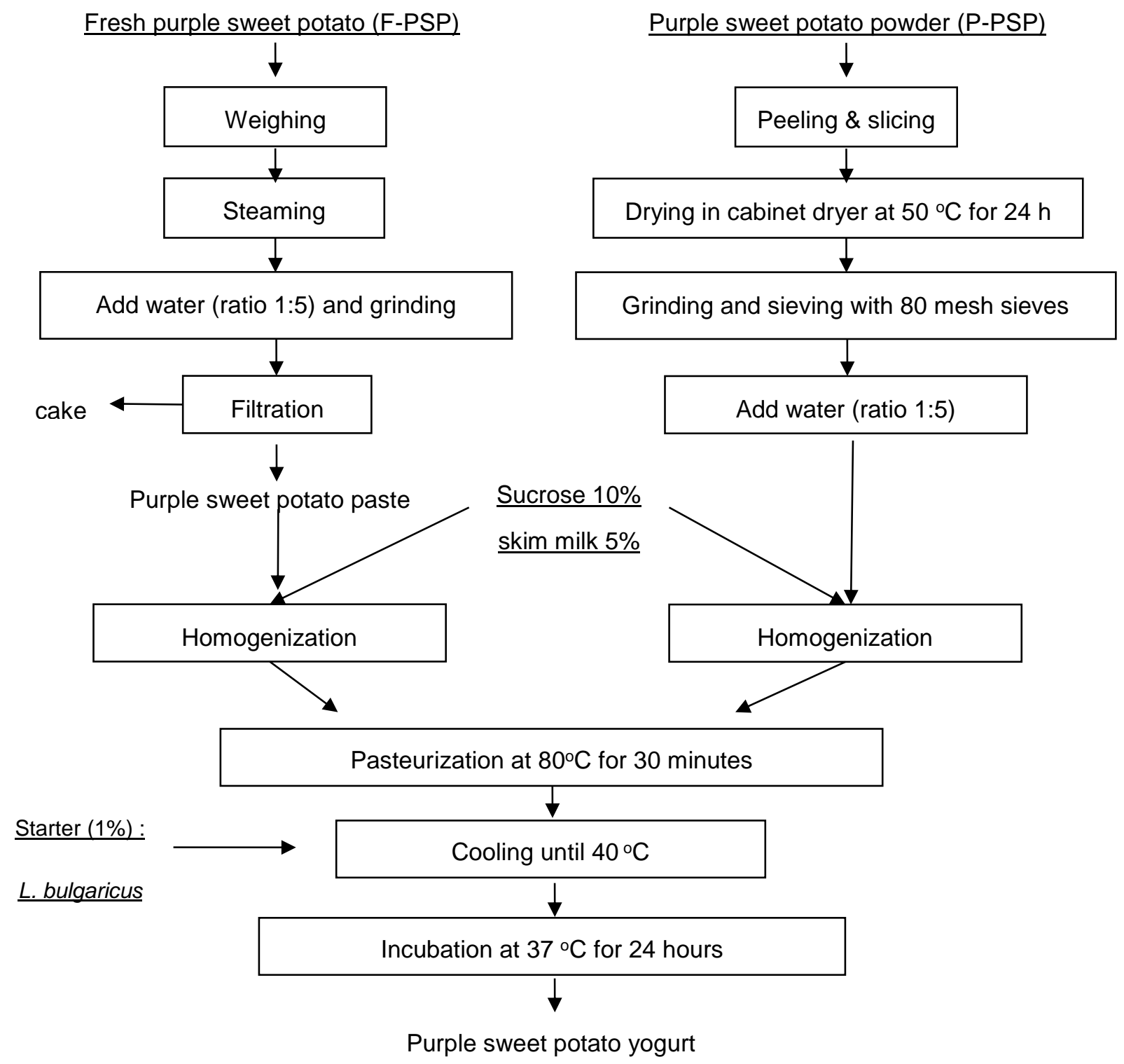

Figure 1. Yogurt Processing. Note: Two variants of sweet potato yogurt were made from fresh sweet potato and sweet potato powder. After the preparation of sweet potato paste, the starter was added as much as $1 \%$ consisting of Lactobacillus bulgaricus and Streptococcus thermophilus at the same proportion.

\subsection{Physical, chemical and microbiological analysis}

The viscosity of purple sweet potato was determined using Brookfield viscometer. $\mathrm{pH}$ value was determined with $\mathrm{pH}$ meter. Total titratable acid was determined using the method described by Nielsen [6]. Water content, protein, lipid, ash, and total carbohydrate were determined using standard method from Association of Official Analytical Chemists (AOAC) (Nielsen, 2003). Total anthocyanins were determined using the spectrophotometry method described by Markakis [7]. The antioxidant activity was determined using DPPH (2,2-diphenyl-1-picrylhydrazyl) method described by Molyneux [8]. Total LAB was determined by classical cultivation method on MRS agar (Merck). 


\subsection{Animal and diet}

Thirty five Sprague Dawley rats were obtained from The Integrated Testing and Research Laboratory, Universitas Gadjah Mada. They were divided into 5 groups of 7 rats. Animals are housed in individual cages in a room maintained at $28 \pm 1^{\circ} \mathrm{C}$, with 12 -h light/dark cycles throughout the experimental period. They were adapted with AIN-93M diets for 1 week and fed with high fat diet for 2 weeks. During feeding with high fat diet, they also receive egg yolk as much as $3 \mathrm{ml} / \mathrm{day}$. At the end of high fat diet feeding, lipid profiles (total cholesterol, triglyceride, LDL, and HDL cholesterol) in serum were determined. The rats received treatment for 4 weeks. The treatment for each groups was arranged as follow: 1) distilled water (CON); 2) yogurt $2 \mathrm{ml} /$ day (YO2); 3 ) yogurt 4 ml/day (YO4); 4) simvastatin $0.8 \mathrm{mg} /$ day (SIM); 5) yogurt $4 \mathrm{ml} /$ day + simvastatin $0.8 \mathrm{mg} /$ day (YSM). Lipid profiles (total cholesterol, triglyceride, LDL, and HDL cholesterol) in serum were determined after 2 and 4 weeks of treatment. The composition of the diet was shown in Table 1. The detail of animal experimental design can be seen in Figure 2.

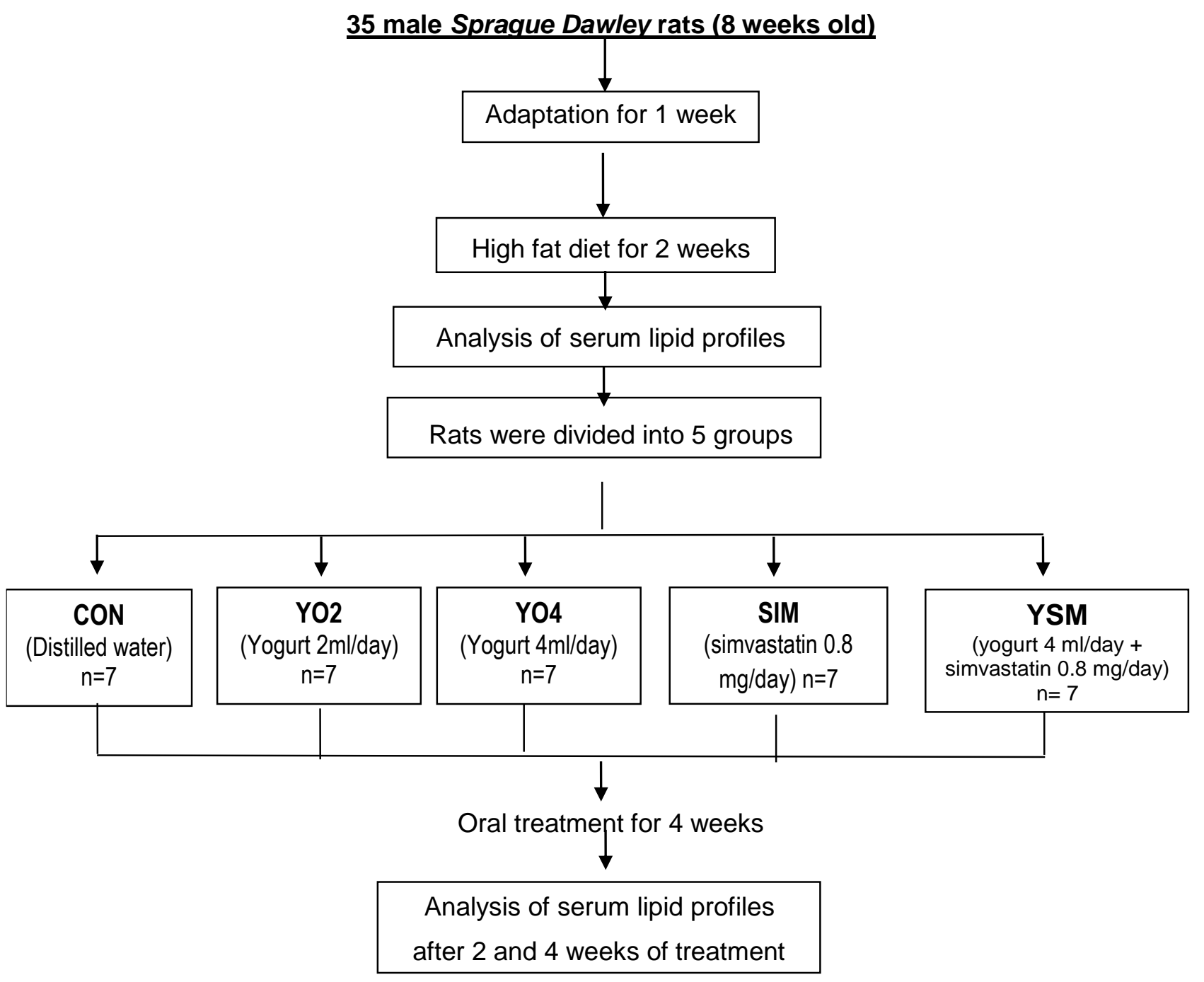

Figure 2. Animal experimental flowchart 
Table 1. Diet composition in grams per kilograms $(\mathrm{g} / \mathrm{kg})$

\begin{tabular}{lcc}
\hline \multicolumn{1}{c}{ Components } & Standard AIN-93M & High Fat Diet \\
\hline Corn Starch $(\mathrm{g})$ & 620.7 & 470,7 \\
Calsium caseinate $(\mathrm{g})$ & 140.0 & 140.0 \\
Sucrose (g) & 100.0 & 100.0 \\
Fiber (g) & 50.0 & 50.0 \\
Soybean Oil (g) & 40.0 & 40.0 \\
AIN-93 Mineral Mix (g) & 35.0 & 35.0 \\
AIN-93 Vitamin Mix (g) & 10.0 & 10.0 \\
Choline Bitartrate (g) & 2.5 & 2.5 \\
L-cystine (g) & 1.8 & 1.8 \\
Coconut oil (g) & - & 150.0 \\
\hline TOTAL (g) & $\mathbf{1 , 0 0 0 . 0 0}$ & $\mathbf{1 , 0 0 0 . 0 0}$ \\
\hline
\end{tabular}

\subsection{Lipid profile analysis}

The blood was collected from re-orbitalis plexus. The blood was centrifuged at $3.000 \mathrm{rpm}$ for 30 minutes to separate the serum. The serum was kept at $-40{ }^{\circ} \mathrm{C}$ until the day of analysis. The total cholesterol, LDL cholesterol, and HDL cholesterol levels were determined with CHOD-PAP methods described by Richmond [9]. Triglyceride was determined with GPO-PAP methods described by McGowan et al. [10]. The reagent kits were obtained from DiaSys Diagnostic System GmBH \& Co, Germany.

\subsection{Statistical analysis}

Each result is expressed as mean \pm standard deviation (SD). T-test was used to assess the statistical significance of differences between 2 variants of purple sweet potato yogurt. One-way ANOVA or Krusskal Wallis was used to assess the statistical significance of differences between groups. Paired t-test or Wilcoxon was used to assess the statistical significance of differences before and after treatments. Each value of $\mathrm{p}<0.05$ is considered to be statistically significant.

\section{RESULTS AND DISCUSSION}

\subsection{Viscosity, $p H$ value and total titratable acid of sweet potato yogurt}

There was a difference between the viscosity of F-PSP and P-PSP yogurt. Viscosity of F-PSP was higher than P-PSP. However, the viscosity of purple sweet potato yogurt was lower than the viscosity of yogurt made from milk. The factors that affect the viscosity of yogurt is the concentration of non fat solids, milk fat, stabilizers, heating process of milk, and starter culture [11]. The viscosity of yogurt is influenced by the amount of skim milk addition. Skim milk was used by lactic acid bacteria as substrates for proliferation. Subsequently, it increased the production of lactic acid so that $\mathrm{pH}$ value decreased and reached \pm 4.6 . At low $\mathrm{pH}$ value, the protein coagulated and formed gel. This will increase the viscosity of yogurt.

The $\mathrm{pH}$ value and total titratable acid between F-PSP and P-PSP yogurt were not significantly different. The $\mathrm{pH}$ value of purple sweet potato yogurt reached 3.46-3.49. According to Buckle et al. [12], yogurt made from milk has $\mathrm{pH}$ value from 4.0-4.5. The low $\mathrm{pH}$ value of F-PSP and P-PSP yogurt were due to the longer incubation time. The activity of lactic acid bacteria (LAB) 
increased during incubation period. The higher lactic acid that was produced by LAB will lower the $\mathrm{pH}$ value. On the contrary, it will increase the total titratable acid. The viscosity, $\mathrm{pH}$ value, and total titratable acid were showed in Table 2.

Table 2. Viscosity, $\mathrm{pH}$ value, and total titratable acid of purple sweet potato yogurt

\begin{tabular}{lccr}
\hline & Variant & \multicolumn{3}{c}{ Parameters } \\
\cline { 2 - 4 } & $\begin{array}{c}\text { Viscosity } \\
(\text { poise })\end{array}$ & $p H$ & Total Titratable Acid \\
\hline F-PSP & $1.73 \pm 0.00^{\mathrm{a}}$ & $3,49^{\mathrm{a}}$ & $1,15^{\mathrm{a}}$ \\
P-PSP & $0.31 \pm 0.00^{\mathrm{b}}$ & $3,46^{\mathrm{a}}$ & $1,19^{\mathrm{a}}$ \\
\hline
\end{tabular}

Note:

F-PSP : purple sweet potato yogurt made from fresh sweet potato

P-PSP : purple sweet potato yogurt made from sweet potato powder

$(a, b) \quad$ : Value containing the same superscript in the same column are not significant $(P>0.05)$.

Results are expressed as the mean \pm S.D. of triplicate.

\subsection{Proximate analysis}

The result of proximate analysis was showed in Figure 3. The proximate value (water, ash, fat, protein, and carbohydrate content) between F-PSP and P-PSP yogurt were not significantly different. This indicated that purple sweet potato yogurt made from fresh sweet potato and sweet potato powder has similar nutrient composition.

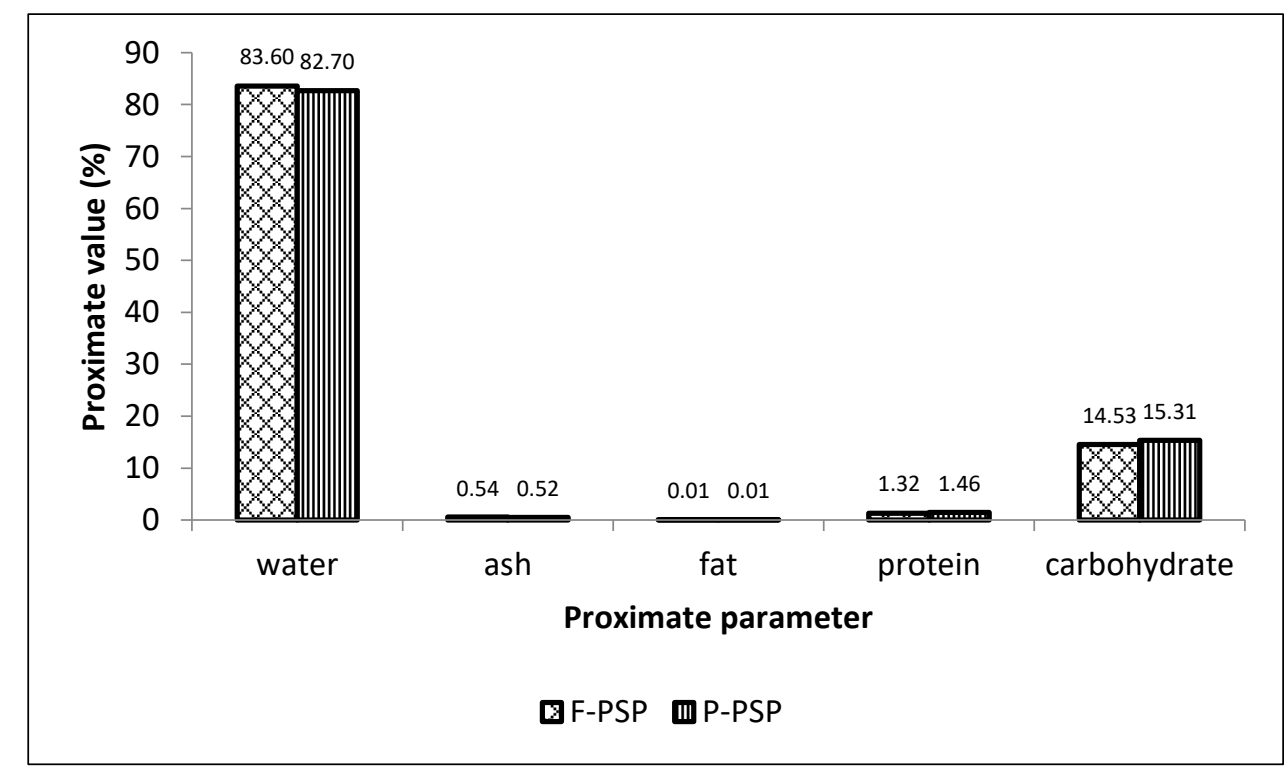

Figure 3. Nutrient composition of purple sweet potato yogurt. Note: F-PSP: purple sweet potato yogurt made from fresh sweet potato, P-PSP : purple sweet potato yogurt made from sweet potato powder. Results are expressed as the mean \pm S.D. of triplicate 


\subsection{Total anthocyanins and antioxidant activity}

Table 3 showed the effect of processing on the total anthocyanins and antioxidant activity of purple sweet potato. Purple sweet potato powder has the highest anthocyanin content, followed by steamed purple sweet potato, raw sweet potato, purple sweet potato paste, F-PSP yogurt, and P-PSP yogurt. The anthocyanins content of purple sweet potato yogurt was lower than its constituent (PSP paste or powder) because there was an addition of water with ratio of 1:5. According to Vargaz and Lopez [13], the stability of anthocyanin was affected by oxygen and light. Food containing anthocyanin should be processed in low temperature, limited oxygen and light condition.

Table 3. Effect of processing on the total anthocyanins and antioxidant activity of purple sweet potato

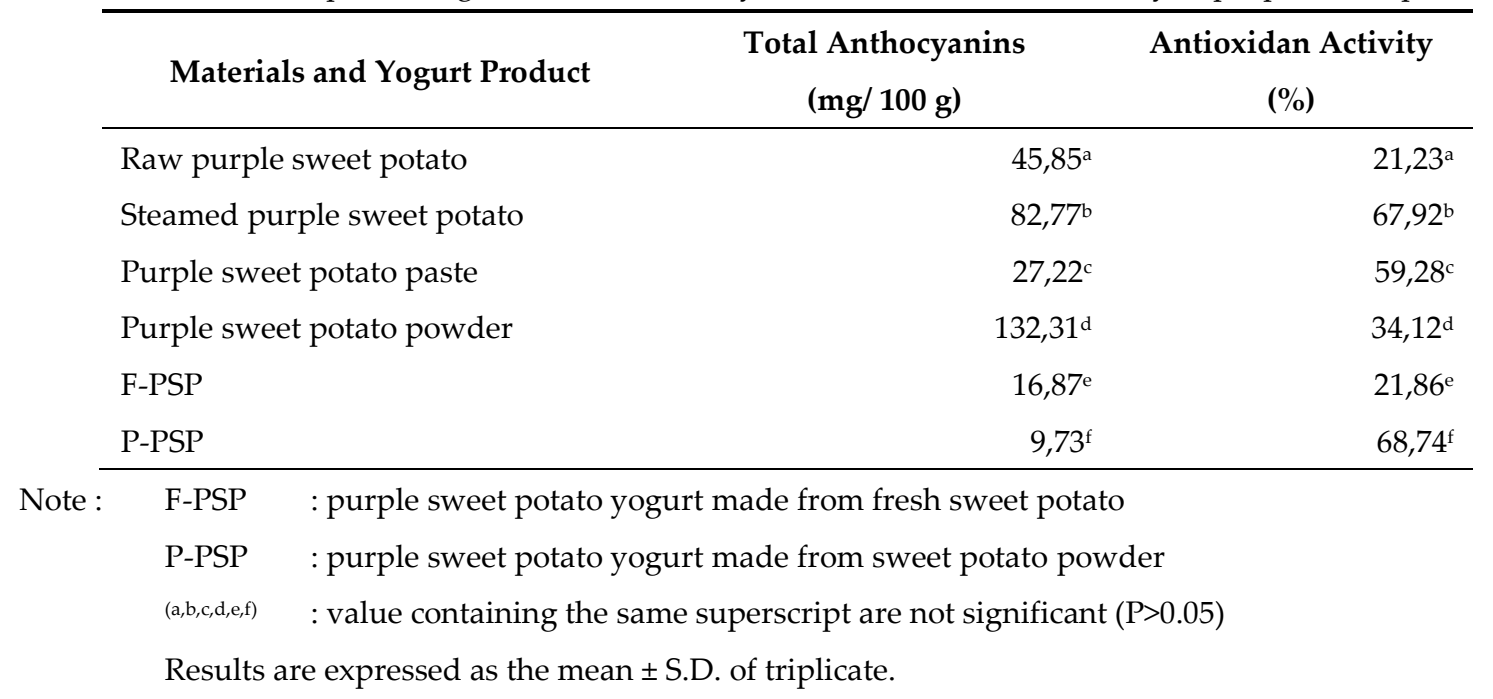

P-PSP yogurt has the highest antioxidant activity, followed by steamed purple sweet potato, purple sweet potato paste, purple sweet potato powder, F-PSP yogurt, and raw purple sweet potato. The highest antioxidant activity of P-PSP yogurt was due to the heating process that might increase the antioxidant activity. According to Kim et al. [14], heating process play an important role in increasing antioxidant activity of polyphenol and flavonoid substances. The antioxidant activity increase after heating at $100{ }^{\circ} \mathrm{C}$ for 20-30 minutes, however it decrease after heating for 40 minutes [15].

Overall, F-PSP yogurt has better characteristic in viscosity and total anthocyanin, however its antioxidant activity was lower than P-PSP yogurt. The $\mathrm{pH}$ value, total titratable acid, and proximate value were similar. The appearance of F-PSP yogurt was better than P-PSP yogurt. F-PSP yogurt has a pink color, whereas P-PSP yogurt has brownish pink color. The organoleptic properties of these yogurt need to be assessed to support their physical and chemical properties.

\subsection{Total lactic acid bacteria analysis}

Figure 4 show that total LAB of F-PSP was different with P-PSP yogurt. Total LAB of F-PSP yogurt was $9.11 \log$ CFU/g, while total LAB of P-PSP yogurt was $8.34 \mathrm{log}$ CFU/g. Total LAB of F-PSP was higher than P-PSP yogurt. It might be due to the browning reaction in powdering process. Browning reaction causes caramelization of monosaccharide so it's difficult to be fermented [12]. Powdering process also decreases solubility of fiber in solution. The particle size of fiber and its solubility will affect the ability of fiber to be fermented by bacteria. 


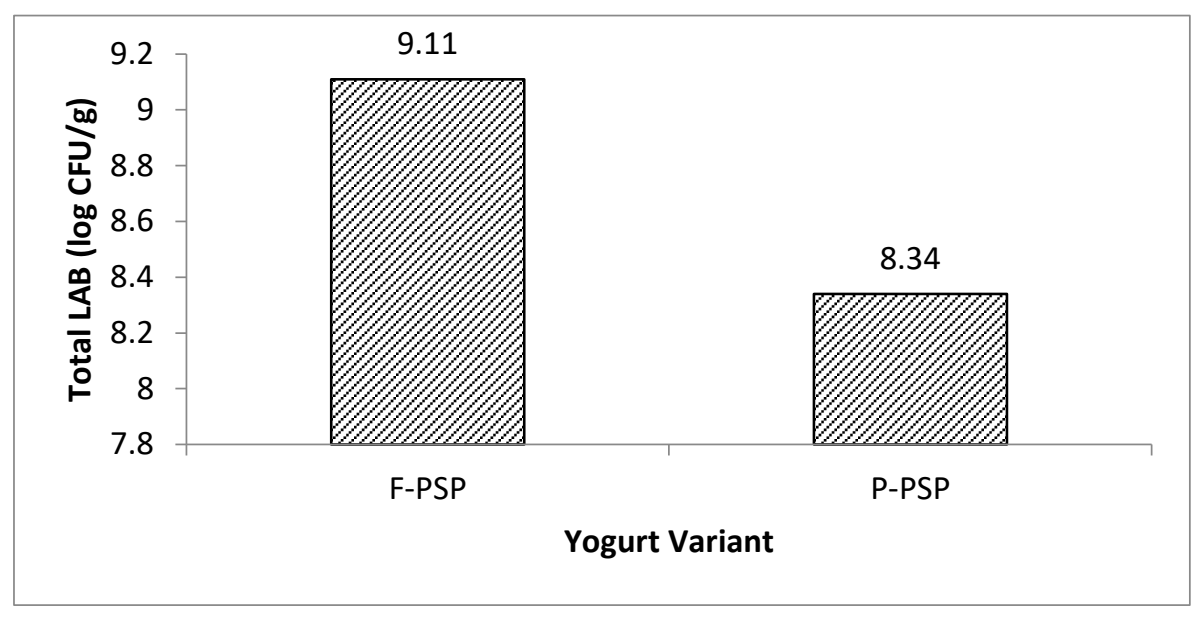

Figure 4. Total LAB of purple sweet potato yogurt. Note : F-PSP : purple sweet potato yogurt made from fresh sweet potato, P-PSP : purple sweet potato yogurt made from sweet potato powder. Results are expressed as the mean \pm S.D. of triplicate

\subsection{Lipid profiles of Sprague Dawley rats}

Based on the product development of purple sweet potato yogurt, F-PSP yogurt has better properties compared to P-PSP yogurt so that F-PSP yogurt was then administered to animal model to know its effect on the lipid profile of Sprague Dawley rats.

The results showed that the total serum cholesterol level in the group given oral administration F-PSP yogurt was not significantly different compared to control group ( $\mathrm{P}>0.05)$. However, when the total cholesterol level was compared between before and after treatment, there is a significant decrease in the group treated with F-PSP yogurt $(\mathrm{P}<0.05)$. The reduction of total cholesterol level in the control group and simvastatin group were not significantly different ( $P>0.05)$. The total cholesterol level during the experiment was shown in Table 4 . The average of total cholesterol levels after fed with high-fat diet were ranged from 52.73 to $79.77 \mathrm{mg} / \mathrm{dl}$. According to Gross [16], total cholesterol levels in Sprague Dawley rats were ranging from $47-88 \mathrm{mg} / \mathrm{dl}$. We assumed that feeding with high-fat diet could not increase the cholesterol level in rats, therefore the treatment could not decrease the total cholesterol level significantly.

Table 4. Total cholesterol level in serum

\begin{tabular}{|c|c|c|c|c|c|c|}
\hline \multirow[t]{2}{*}{ Period } & \multicolumn{5}{|c|}{ Treatments } & \multirow{2}{*}{$\left.\mathbf{P}^{*}\right)$} \\
\hline & $\mathrm{CON}$ & YO2 & YO4 & SIM & YSM & \\
\hline $\begin{array}{c}\text { Before } \\
\text { treatment (a) }\end{array}$ & $52.73 \pm 7.33$ & $63.81 \pm 10.28$ & $74.43 \pm 23.73$ & $67.25 \pm 14.07$ & $79.76 \pm 20.03$ & 0.730 \\
\hline 2 weeks (b) & $35.55 \pm 3.67$ & $43.46 \pm 9.01$ & $44.95 \pm 5.36$ & $41.60 \pm 8.57$ & $44.21 \pm 5.53$ & 0.143 \\
\hline 4 weeks (c) & $43.23 \pm 6.87$ & $53.38 \pm 14.70$ & $50.15 \pm 8.83$ & $53.53 \pm 8.14$ & $57.05 \pm 18.45$ & 0.383 \\
\hline Delta $(c-a)$ & $-9.50 \pm 9.31$ & $-10.43 \pm 8.27$ & $-24.28 \pm 19.90$ & $-13.71 \pm 14.13$ & $-22.71 \pm 19.39$ & 0.690 \\
\hline $\left.\mathrm{P}^{* *}\right)$ & 0.028 & 0.028 & 0.028 & 0.046 & 0.028 & \\
\hline $\left.\mathrm{P}^{* * *}\right)$ & 0.075 & 0.046 & 0.028 & 0.075 & 0.028 & \\
\hline
\end{tabular}

Note: $\left.\mathrm{P}^{*}\right)$ : the $\mathrm{P}$ value between groups

$\left.P^{* *}\right)$ : the $P$ value between before treatment and after 2 weeks of treatment $\left.\mathrm{P}^{* * *}\right)$ : the $\mathrm{P}$ value between before treatment and after 4 weeks of treatment Results are expressed as the mean \pm S.D. of seven rats. 
Table 5. Triglyceride level in serum

\begin{tabular}{|c|c|c|c|c|c|c|}
\hline \multirow[t]{2}{*}{ Period } & \multicolumn{5}{|c|}{ Treatments } & \multirow{2}{*}{$\left.P^{*}\right)$} \\
\hline & $\mathrm{CON}$ & YO2 & YO4 & SIM & YSM & \\
\hline $\begin{array}{l}\text { Before } \\
\text { treatments (a) }\end{array}$ & $207.41 \pm 46.73$ & $132.95 \pm 60.64$ & $191.23 \pm 116.49$ & $135.70 \pm 58.21$ & $162.8 \pm 27.85$ & 0.266 \\
\hline 2 weeks (b) & $95.83 \pm 39.12$ & $96.81 \pm 28.20$ & $111.91 \pm 29.62$ & $81.73 \pm 50.93$ & $85.41 \pm 41.54$ & 0.698 \\
\hline 4 weeks (c) & $89.45 \pm 39.85$ & $71.36 \pm 19.50$ & $122.85 \pm 34.79$ & $72.55 \pm 50.37$ & $104.68 \pm 18.71$ & 0.079 \\
\hline Delta $(c-a)$ & $-117.96 \pm 69.93$ & $-61.58 \pm 53.80$ & $-68.38 \pm 113.42$ & $-63.15 \pm 48.18$ & $-58.11 \pm 24.57$ & 0.309 \\
\hline $\left.\mathrm{P}^{* *}\right)$ & 0.028 & 0.046 & 0.046 & 0.028 & 0.046 & \\
\hline $\left.\mathrm{P}^{* * *}\right)$ & 0.046 & 0.028 & 0.028 & 0.028 & 0.028 & \\
\hline
\end{tabular}

Note: $\left.\mathrm{P}^{*}\right)$ : the $\mathrm{P}$ value between groups

$\left.\mathrm{P}^{* *}\right)$ : the $\mathrm{P}$ value between before treatment and after 2 weeks of treatment

$\left.\mathrm{P}^{* * *}\right)$ : the $\mathrm{P}$ value between before treatment and after 4 weeks of treatment

Results are expressed as the mean \pm S.D. of seven rats.

Table 5 showed that the triglyceride levels in the group given oral administration F-PSP yogurt were not significantly different compared to control group $(\mathrm{P}>0.05)$. Similar to the total cholesterol level, the reduction of triglyceride before and after treatment was also significantly different $(\mathrm{P}<0.05)$. After 4 weeks of treatments, triglyceride levels in all groups had a significant decrease ( $p$ value $<0.05$ ), although it was not significantly different between groups.

As it was seen in Table 6, the reduction of LDL cholesterol level in the group treated with 4 $\mathrm{ml}$ of F-PSP yogurt, simvastatin, and F-PSP yogurt + simvastatin were significantly higher than the control group. The highest reduction of LDL cholesterol levels were found in the group treated with $2 \mathrm{ml}$ of yogurt $(11.98 \mathrm{mg} / \mathrm{dL})$ and followed by $4 \mathrm{ml}$ of yogurt $(11.84 \mathrm{mg} / \mathrm{dL}), 4 \mathrm{ml}$ of yogurt + simvastatin $(11.48 \mathrm{mg} / \mathrm{dL})$, simvastatin $(8.4 \mathrm{mg} / \mathrm{dL})$. HDL cholesterol levels in the yogurt group decreased after 2 weeks of treatment, but it increased after 4 weeks of treatment. After 4 weeks of treatment, the HDL cholesterol level in the group treated with $4 \mathrm{ml}$ yogurt has the lowest reduction compared with the others (Table 7).

Table 6. LDL cholesterol level in serum

\begin{tabular}{lrrrrrr}
\hline \multirow{2}{*}{ Period } & \multicolumn{7}{c}{ Treatments } & \multirow{2}{*}{ P*) } \\
\cline { 2 - 6 } & \multicolumn{1}{c}{ CON } & \multicolumn{1}{c}{ YO2 } & \multicolumn{1}{c}{ YO4 } & SIM & YSM & \\
\hline Before & & & & & & 0.030 \\
treatment & & & & & & \\
(a) & $25.58 \pm 7.41$ & $47.66 \pm 17.27$ & $36.26 \pm 6.47$ & $36.10 \pm 3.62$ & $30.18 \pm 6.91$ & \\
2 weeks (b) & $16.84 \pm 2.89$ & $22.22 \pm 6.21$ & $22.44 \pm 4.35$ & $21.24 \pm 4.83$ & $21.90 \pm 2.97$ & 0.170 \\
4 weeks (c) & $19.08 \pm 6.24$ & $31.18 \pm 11.27$ & $24.42 \pm 6.64$ & $27.70 \pm 5.29$ & $21.00 \pm 3.51$ & 0.125 \\
\hline Delta (c-a) & $-6.5 \pm 5.9$ & $-16.48 \pm 11.78$ & $-11.84 \pm 6.63$ & $-8.4 \pm 6.21$ & $-9.18 \pm 8.91$ & \\
\hline$\left.P^{* *}\right)$ & 0.065 & 0.028 & 0.006 & 0.001 & 0.110 & \\
\hline$P^{* * *)}$ & 0.072 & 0.035 & 0.016 & 0.039 & 0.083 & \\
\hline & & & & & &
\end{tabular}

Note: $\left.\mathrm{P}^{*}\right)$ : the $\mathrm{P}$ value between groups

$\left.\mathrm{P}^{* *}\right)$ : the $\mathrm{P}$ value between before treatment and after 2 weeks of treatment $\left.\mathrm{P}^{* * *}\right)$ : the $\mathrm{P}$ value between before treatment and after 4 weeks of treatment Results are expressed as the mean \pm S.D. of seven rats. 
Table 7. HDL cholesterol level in serum

\begin{tabular}{lrrrrrr}
\hline \multirow{2}{*}{ Period } & \multicolumn{7}{c}{ Treatments } & P \\
\cline { 2 - 6 } & \multicolumn{1}{c}{ CON } & \multicolumn{1}{c}{ YO2 } & \multicolumn{1}{c}{ YO4 } & SIM & YSM & \\
\hline Before treatment & & & & & & \\
(a) & $22.36 \pm 2.18$ & $25.88 \pm 4.49$ & $26.60 \pm 2.87$ & $27.62 \pm 2.12$ & $27.46 \pm 1.91$ & \\
2 weeks (b) & $18.02 \pm 2.67$ & $18.38 \pm 5.40$ & $17.80 \pm 2.69$ & $18.88 \pm 3.72$ & $21.86 \pm 1.60$ & 0.476 \\
4 weeks (c) & $19.92 \pm 6.38$ & $27.64 \pm 5.40$ & $24.12 \pm 3.06$ & $21.56 \pm 5.18$ & $22.76 \pm 1.61$ & 0.333 \\
\hline Delta (c-a) & $-2.44 \pm 5.33$ & $1.76 \pm 7.60$ & $-2.48 \pm 3.23$ & $-5.76 \pm 2.19$ & $-4.7 \pm 1.87$ & \\
\hline$P^{* * *}$ & 0.015 & 0.08 & 0.012 & 0.011 & 0.023 \\
\hline$P^{* * *)}$ & 0.364 & 0.632 & 0.161 & 0.04 & 0.005 \\
\hline
\end{tabular}

Note: $\mathrm{P}^{*}$ ) : the $\mathrm{P}$ value between groups

$\left.\mathrm{P}^{* *}\right)$ : the $\mathrm{P}$ value between before treatment and after 2 weeks of treatment

$\left.\mathrm{P}^{* * *}\right)$ : the $\mathrm{P}$ value between before treatment and after 4 weeks of treatment

Results are expressed as the mean \pm S.D. of seven rats.

Purple sweet potato yogurt contained some bioactive components that could reduce cholesterol levels such as anthocyanin, dietary fiber, and lactic acid bacteria. However, the results of this study were not in line with other research. This might be due to cholesterol levels after the rats given high fat diet is still considered in the normal range. Thereby, yogurt can be said to have homeostasis effect. On the other hand, the early studies showed the combination of diet and exercise could increase HDL cholesterol significantly. There was no significant change of HDL cholesterol in subject that managed their diet without exercise [17].

Lactic acid bacteria in purple sweet potato yogurt may reduce the serum cholesterol level through bacterial assimilation in the intestine [18], binding of cholesterol to the bacterial cell wall, and deconjugation of bile salts (19-21), as well as production of short chain fatty acid [22]. Certain lactic acid bacteria such as Lactobacillus acidophilus and L. plantarum could act directly on cholesterol in the gastrointestinal tract, and thus could reduce the serum cholesterol level. The cholesterol-lowering effects of LAB can be ascribed to Bile Salts Hydrolase (BSH) activity. Deconjugation of bile salts are less absorbed than their conjugated form and therefore, they will be excreted as free bile acids in feces. The free bile salts are also less efficient in the solubilization and absorption of lipids in the intestinal tract. Short chain fatty acids produced by Lactobacilli may also inhibit hepatic cholesterol synthesis and distribution of cholesterol in the plasma and liver [22]. Serum acetate and propionate concentrations were related to serum lipid concentrations in both males and females, serum propionate being strongly negatively related to both total and LDL cholesterol [23]. In addition, purple sweet potato yogurt contains anthocyanin that could act as antioxidant. Antioxidants could delay the lipid peroxidation process in propagation phase [24]. Qin et al. [25] found that anthocyanin supplementation in human volunteers improves LDL- and HDL-cholesterol concentrations and enhances cellular cholesterol efflux to serum. This might be due to the inhibition of cholesteryl ester transfer protein (CETP).

Clinical studies using various lactic acid bacteria have given various results and thus do not allow any general conclusion. Some strains of lactic acid bacteria could lower the serum cholesterol level, while others could not. The different results between research were due to different strain of $\mathrm{LAB}$, doses, and experimental design. 


\section{CONCLUSION}

Yogurt made with fresh purple sweet potato has better physical, chemical and microbiological properties compared to yogurt made with its powder form. The serum cholesterol and triglyceride levels in the group given oral administration of purple sweet potato yogurt was not significantly different compared to control group $(\mathrm{P}>0.05)$. However, the reduction of serum LDL cholesterol level in the group treated with yogurt was significantly higher than the control group. The serum HDL cholesterol in the yogurt group decreased after 2 weeks of treatment, but it increased after 4 weeks of treatment. Due to its ability to reduce the LDL cholesterol level, purple sweet potato yogurt could be used as an alternative functional food that could lower blood cholesterol levels.

Funding: This research was partly funded by Faculty of Medicine, Public Health, and Nursing, Universitas Gadjah Mada University granted to Dr. Lily Arsanti Lestari.

Acknowledgments: I would like to express my gratitude to the technicians and analyst in Laboratory of Microbiology, Center for Food and Nutrition Studies, Universitas Gadjah Mada; Laboratory of Nutrition Analysis in Faculty of Medicine, Public Health, and Nursing for their support.

Conflicts of interest: The authors declare no conflict of interest.

\section{REFERENCES}

1. Brown, L., Rosner, B., Willett, WW., \& Sacks, FM. Cholesterol-lowering effects of dietary fiber: a meta-analysis. Am J Clin Nutr. 1999. 69: 30-42.

2. Krummel, D.A. Medical nutrition therapy for cardiovascular diseases. In: Mahan, L.K.\& Escott-Stump, S. (eds.). Krause's Food and Nutrition Therapy, 12 ${ }^{\text {th }}$ ed. Missouri: Saunders Elsevier, 2008. pp. 837-846.

3. Woolfe, J. Sweet Potato: An Untapped Food Resource. Cambridge University Press, Cambridge. 1993.

4. Lohachoompol, V., Srzednicki, G., \& Craske, J. The Change of Total Anthocyanins in Blueberries and Their Antioxidant Effect After Drying and Freezing. J Biomed Biotechnol. 2004. 5: 248-252.

5. Kim, S.Y., Jeong, S-M, Kim, S-J, Jeon, K-I, Park, E-J ,Park, H-R \& Lee, S-C. Effect of Heat Treatment on the Antioxidative and Antigenotoxic Activity of Extracts from Persimmon (Diospyros kaki L.) Peel. Biosci. Biotechnol. Biochem. 2006, 70 : 999-1002.

6. Nielsen, S.S. Food Analysis. Kluwer Academic, New York. 2003.

7. Markakis, P. Anthocyanins as Food Colors. Academic Press, Inc., London. 1982.

8. Molyneux, P. The Use of Stable Free Radikal Dipphenylpicrilhidrazyl (DPPH) for Estimating Antioxidant Activity, J. Sci. Technol. 2004. 26: 211-219.

9. Richmond, W. Enzymatic determination of total serum cholesterol. Clin. Chem. 1973. 19: 1350-1354.

10. McGowan, M.W., Artiss, J.D., \& Stanbergh, R.Z. A peroxide-coupled methods for the colorimetric determination of serum triglyceride. Clin. Chem. 1983. 29: 538-542.

11. Vedamuthu. E.R. Fermented milk. In A.H. Rose (Ed). Fermented Foods. Academic Press Inc. Ltd., London. 1982.

12. Buckle, K.A., Edward, R.A., Fleet, G.H., \& Wootton, M. Food Science. Indonesian translation by Hadi Purnomo and Adiono. UI Press, Jakarta. 2009.

13. Vargaz, F. D. \& Lopez, O.P. Natural Colorants for Food and Nutraceutial Uses. CRC Press, USA. 2003.

14. Kim, S.Y., Jeong, S-M, Kim, S-J, Jeon, K-I, Park, E-J ,Park, H-R \& Lee, S-C. Effect of Heat Treatment on the Antioxidative and Antigenotoxic Activity of Extracts from Persimmon (Diospyros kaki L.) Peel. Biosci. Biotechnol. Biochem., 2006. 70 : 999-1002.

15. Santoso, U., Setyaningsih, E., \& Cahyanto, M.N. Pengaruh Pemanasan Pada Aktivitas Antioksidan Ekstrak Etanol. Jurnal Agritech, 2006. Vol XXVI. 
16. Gross, D.R. Animal Model in Cardiovaskuler Research. Springer Science and Bussiness Media, New York. 2009.

17. Paul, T.W., Ronald, M.K., Marcia, L.S., Karen, M.V., \& Peter, D.W. Effects of Low-Fat Diet, Calorie Restriction, and Running on Lipoprotein Subfraction Concentrations in Moderately Overweight Men. Metabolism. 1994. 43(5): 655-663.

18. Gilliland, S.E., Nelson, C.R., \& Maxwell, C. Assimilation of cholesterol by Lactobacillus acidophilus. Appl. Environ. Microbiol., 1985. 49: 377-381.

19. Klaver FA \& van De Meer, R. The assumed assimilation of cholesterol by Lactobacilli and Bifidobacterium bifidum is due to their bile salts-deconjugating activity. Appl. Environ. Microbiol., 1993. 59: 1120-1124.

20. De Smet, I, De Boever, P, \& Verstraete, W. Cholesterol lowering in pigs through enhanced bacterial bile hydrolase activity. Br. J. Nutr., 1998. 79: 185-194.

21. Liong, M. T., \& Shah, N. P. Bile salt deconjugation ability, bile salt hydrolase activity and cholesterol co-precipitation ability of lactobacilli strains. Int. Dairy J. 2005. 15:391-398.

22. Pereira, D.I. \& Gibson, G.R. Effects of consumption of probiotic and prebiotics on serum lipid levels in humans. Crit. Rev. Biochem. Mol. Biomol. 2002. 37: 259-281.

23. Wolever, T.M.S., Fernandes, J., \& Veketeshwer Rao, A. Serum acetate: propionate ratio is related to serum cholesterol in men but not in women. J. Nutr. 1996. 126: 2790-2797.

24. Sodergren, E. Lipid Peroxidation in vivo: evaluation and application of methods for measurement. Undergraduate thesis of University Upsaliensis, Uppsala. 2000.

25. Qin, Y., Xia, M., Ma, J., Hao, Y.T., Liu, J., Mou, H.Y., Cao, L., \& Ling, W.H. Anthocyanin supplementation improves serum LDL- and HDL-cholesterol concentrations associated with the inhibition of cholesteryl ester transfer protein in dyslipidemic subjects. Am. J. Clin. Nutr. 2006. 90:485-92.

(C) 2020 by the authors. Submitted for possible open access publication under the terms and conditions of the Creative Commons Attribution (CC BY) license (http://creativecommons.org/licenses/by/4.0/). 